\title{
Illuminating and mitigating the evolving impacts of COVID-19 on ethnocultural communities: a participatory action mixed-methods study
}

\author{
Denise Campbell-Scherer MD PhD, Yvonne Chiu PhD, Nicole Naadu Ofosu PhD, Thea Luig PhD, \\ Karen Heather Hunter PhD, Badi Jabbour BSc, Sauleha Farooq BSc, Ali Mahdi MEcon, Aline Gayawira BA, \\ Fransiska Awasis, Funke Olokude RSW MEd, Hannah Goa MSc, Hina Syed BA, Judy Sillito MEd, Lydia Yip, \\ Lyn Belle RSW, Mawien Akot MB ChB, Monique Nutter BA MSW, Nadia Farhat, Yan Wang MA, Niga Jalal BA, \\ Saida Khalif BScN, Shiva Chapagain, Stephanie Fernandez MD, Susan Azarcon BSc, Zhewar Hama BArch
}

Cite as: CMAJ 2021 August 9;193:E1203-12. doi: 10.1503/cmaj.210131

\begin{abstract}
BACKGROUND: The COVID-19 pandemic has exacerbated disparities in poverty and illness for people in vulnerable circumstances in ethnocultural communities. We sought to understand the evolving impacts of COVID-19 on ethnocultural communities to inform intersectoral advocacy and community action.
\end{abstract}

METHODS: The Illuminate Project used participatory action research, with cultural health brokers as peer researchers, from Sept. 21 to Dec. 31, 2020, in Edmonton, Alberta. Twentyone peer researchers collected narratives from members of ethnocultural communities and self-interpreted them as they entered the narratives into the
SenseMaker platform, a mixed-method data collection tool. The entire research team analyzed real-time, aggregate, quantitative and qualitative data to identify emerging thematic domains, then visualized these domains with social network analysis.

RESULTS: Brokers serving diverse communities collected 773 narratives. Identified domains illuminate the evolving and entangled impacts of COVID-19 including the following: COVID-19 prevention and management; care of acute, chronic and serious illnesses other than COVID19; maternal care; mental health and triggers of past trauma; financial insecurity; impact on children and youth and seniors; and legal concerns. We identified that community social capital and cultural brokering are key assets that facilitate access to formal health and social system supports.

INTERPRETATION: The Illuminate Project has illustrated the entangled, systemic issues that result in poor health among vulnerable members of ethnocultural communities, and the exacerbating effects of COVID-19, which also increased barriers to mitigation. Cultural brokering and community social capital are key supports for people during the COVID-19 pandemic. These findings can inform policy to reduce harm and support community resiliency.

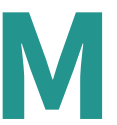

ahatma Gandhi observed that "the true measure of any society can be found in how it treats its most vulnerable members." Ethnocultural communities, defined by their unique shared characteristics (e.g., cultural traditions, language, country of origin), ${ }^{1}$ face greater challenges and have higher rates of poverty and illness than the general Canadian population. Migration results in conditions that affect all social determinants of health and disproportionally affect health outcomes, herein referred to as vulnerable circumstances. ${ }^{2,3}$ The emergence of major outbreaks of SARS-CoV-2 infections in ethnocultural communities highlights both the vulnerable circumstances of these communities and the disparities they face in accessing high-quality, culturally appropriate information and support. ${ }^{4-7}$ Studies have shown substantial variation in deaths attributed to COVID-19 based on factors such as age, sex, ethnicity, length of time in Canada, income and education. ${ }^{8-11}$ However, given the well-known gap in reporting comprehensive COVID-19 data in relation to race and ethnicity, efforts to measure its impact are hampered. ${ }^{8-12}$ There is an urgent need to understand the evolving challenges of COVID-19 to inform action and public policy that can mitigate these challenges. 
To understand evolving situations of complexity and crisis, sensemaking, defined as "a continuous process to establish situational awareness, ${ }^{13}$ is a crucial undertaking. ${ }^{14}$ Using participatory action research, ${ }^{15-18}$ we sought to understand the evolving impacts of COVID-19 on ethnocultural communities to inform broader national efforts to migitate the impacts of COVID-19. Particularly, we sought to understand how the challenges of COVID-19 are entangled with contextual factors at multiple levels, how families and communities are leveraging strengths and social capital to adapt, and the role of cultural brokers in managing the crisis.

\section{Methods}

We report our mixed-methods study according to the Good Reporting of A Mixed Methods Study (GRAMMS) checklist. ${ }^{19}$

\section{Setting and participants}

Academic researchers from the University of Alberta partnered with the Multicultural Health Broker Cooperative (MCHB) in Edmonton, Alberta, operated by community health workers of immigrant and refugee backgrounds, ${ }^{20}$ to conduct a communitybased $^{15,17,18}$ and trauma-informed participatory action research ${ }^{17,21}$ project. For 23 years, the MCHB's mission has been to support immigrant and refugee families to attain optimum health through health education, holistic family support, community development, and system advocacy. The MCHB has a history of advocacy to reduce health inequities. Collectively, the MCHB brokers speak 54 languages and serve more than 10000 people from dozens of ethnolinguistic communities.

Cultural brokering $20,22,23$ is defined as "the act of bridging, linking, mediating between groups or persons of differing cultural backgrounds for the purpose of reducing conflict and producing change." ${ }^{20}$ It is grounded in democratic governance, direct responsiveness and accountability, equity and social justice. Cultural brokers bridge cultural distance, ${ }^{20,24}$ which refers to differences in values, communication styles, experiences and social organization, rooted in culture. Brokers are embedded in ethnocultural immigrant and refugee communities and share lived experiences of migration, trauma and finding themselves in vulnerable conditions while building their lives in Canada. Thus, they possess a deep knowledge of culture, premigration context and postmigration stressors, as well as gender and power relations. Brokers work with people in vulnerable circumstances, and are ideally situated to capture nuanced, real-time observations of the lived reality of community members and the impact of COVID-19 on communities as peer researchers.

Peer researchers were invited by the executive director of the $\mathrm{MCHB}$ and project colead (Y.C.) using purposive sampling criteria, as shown in Appendix 1, available at www.cmaj.ca/lookup/doi /10.1503/cmaj.210131/tab-related-content. The demands of COVID-19 meant that about $20 \%$ of all brokers had capacity to take on this additional work. Peer researchers contributed to every phase of the project, including its inception and purpose, instrument design, data collection and analysis, weekly sensemaking sessions, policy suggestions, and manuscript writing and revision.

\section{Study design and theoretical considerations}

To address the interconnected research purposes of understanding a complex problem and informing action for impact, ${ }^{25}$ we used a partnership-based, integrated, mixed-methods approach ${ }^{26}$ with an action research design. ${ }^{27}$ We captured real-time data to inform ongoing group reflection and understanding, or "sensemaking." Sensemaking, informed by the Cynefin framework, ${ }^{28}$ is emerging as a pragmatic and participatory action research approach to study crises. The intent of this approach is to understand entangled, evolving phenomena to inform decision-making for action in complex spaces and to address complex problems..$^{14,29,30}$ It is based on the notion that humans live in complex adaptive systems and make sense of the world using narrative. ${ }^{25,31}$ This approach starts with a concern identified by the community and involves collecting qualitative and quantitative evidence to achieve sufficient insight to support action. It has an exploratory focus on improving a situation, with subsequent cycles of data collection, analysis, and reflection. It embraces a collaborative and reflective relationship between participants and the researcher conducting activities, with an intent to improve social conditions.. ${ }^{27}$

We were guided by the principles of community-based and trauma-informed participatory action research. ${ }^{15,17,18,21}$ Our data collection instrument and analysis drew upon the following concepts: syndemic theory, ${ }^{32-34}$ which acknowledges the aggravating effects of the interaction of 2 or more diseases within harmful social conditions; salutogenesis, ${ }^{35,36}$ which highlights manageability, meaningfulness and coherence (making sense of things) as vital to sustaining and fostering health within crisis; and resilience, ${ }^{37}$ a sociological concept focusing on mobilization of resources and shifting of risks. This approach uses narratives differently than traditional research based on narrative data, ${ }^{31,38,39}$ capturing data in the form of large numbers of micronarratives, rather than a small number of in-depth narratives.

\section{Data collection and analysis}

The project progressed in the following 3 phases: clarification of the purpose, collaboration and methods of the project; co-creation and refinement of the data collection tool; and iterative, real-time data collection and data analysis by the entire team during weekly meetings, illustrated in Figure 1.

\section{Team-based weekly sensemaking sessions}

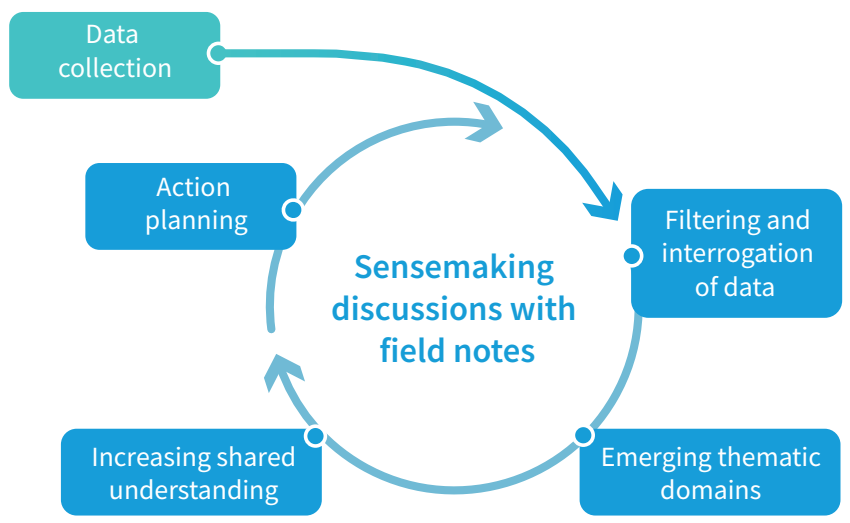

Figure 1: Phase 3: iterative, real-time data collection and analysis. 
In phase 1, we built upon an existing collaboration between the MCHB and the academic researchers. When the COVID-19 pandemic began, the $\mathrm{MCHB}$ rapidly identified emerging areas of crisis in the community that were not being perceived by the larger formal system (i.e., intentionally designed organizations or institutions, such as the health care, social care, justice or school systems) and highlighted the need to illuminate them. The research team immediately pivoted to support this need. The identified priority areas were COVID-19 infection prevention and management, food insecurity, family violence, mental health, triggers of past trauma, and care of conditions other than COVID-19, including maternal care, acute care, chronic illness care and serious illness care. We recognized that these issues were evolving and more likely emergent in the context of COVID-19.

In phase 2, peer and academic researchers codesigned a data collection tool using SenseMaker (Cognitive Edge), which supports the collection of narratives on smartphones or computers that are then analyzed using mixed methods. ${ }^{29}$ The tool is presented in detail in Appendix 2, available at www.cmaj.ca/lookup/ doi/10.1503/cmaj.210131/tab-related-content. Our peer researchers captured short micronarratives from their lived experience of cultural brokering with families and communities between Sept. 21, 2020, and Dec. 31, 2020. In brief, a prompt is provided to elicit a micronarrative about something the peer researchers experienced in their work that relates to the priority areas or another pressing, emerging concern. They then selfinterpret the narrative using the signifier sets created to categorize the narratives. This is referred to as "signification." The signifier set includes ternary plots, or "triads," and multiple-choice questions. The triads, informed by the project's guiding theories, focused on what was affected (e.g., individual, family or community well-being), risks experienced, health-sustaining factors, resources for support and areas for improvement. We used the multiple-choice questions to categorize the responses by priority area, emotional tone, community, broker role employed, commonness, temporality, source and the degree to which peoples' needs were met. Ultimately, the data are in the form of qualitative, narrative information, compositional data for the triads and categorical data for the multiple-choice questions. The entries take about 8 minutes to complete. Peer researchers were supported by the research team with technical questions and were adept at entry after a couple of narratives. They entered data in a mobile phone app or on a desktop computer interface. Data were stored securely on the Cognitive Edge SenseMaker servers.

In phase 3, we reviewed real-time, aggregate data on the SenseMaker Workbench, which generates visualizations of patterns found in the data, linked to the micronarratives, permitting both quantitative and qualitative exploration. ${ }^{40}$ The entire team, including the academic and peer researchers, met weekly for 90 minutes in a facilitated session to review and reflect on the patterns emerging in the data. We interrogated the data using the multiple-choice categories and clusters in the triads as filters, and by group discussion and reflection on the patterns (i.e., clusters and outliers) and associated narratives. ${ }^{41}$ In this phase, we integrated the quantitative and qualitative data collectively and iteratively. We took field notes to capture interpretations, emerging thematic domains and proposed actions. After 7 meetings, the entire group had achieved a shared understanding of the thematic domains, and the focus of the sensemaking sessions expanded to include suggestions for action. The action planning was guided by the question, "What are the actions that could be taken now at low cost, in the short term with modest investment, and over the longer term with more significant investment, that would make a meaningful difference for people?" Three sessions of intensive discussion, including bringing in a content expert on education, resulted in practical suggestions for policy and community action.

The narratives, signification and discussions showed an entanglement of issues, which were visualized using a nondirectional social network analysis (Fruchterman-Reingold algorithm), after deriving an adjacency matrix from the binary categorical variables coded for each of the 16 issues. ${ }^{42,43}$ Multiple issues and broker roles could be present within a single narrative. We conducted quantitative analyses using IBM SPSS Statistics Version 26.0 and $\mathrm{R}$ version 4.0.3.

\section{Ethics approval}

The project was approved by the University of Alberta Research Ethics Board (Pro00074666).

\section{Results}

Participating brokers and community leaders included 5 men and 16 women. Most participants had 10 or more years of brokering experience. Additional sociodemographic information is shared in Appendix 3, available at www.cmaj.ca/lookup/doi/10.1503/cmaj. 210131/tab-related-content. Brokers collected and signified 773 micronarratives representing the lived experiences of people and families from diverse communities living in vulnerable circumstances in Edmonton, Alberta, between Sept. 21, 2020, and Dec. 31, 2020. These signified micronarratives are illustrated in several triads in Figure 2.

One-third of the narratives pertained directly to the prevention and management of COVID-19. They related to the wellbeing of individuals (19\%), family (15\%), and family and individuals $(36 \%)$, and to a combination of individual, family and community well-being (26\%) (Figure 2A). Figure 2B shows major clusters of actions by which risk was incurred. In the domain of prioritizing current needs (31\% of the narratives), the entwining of COVID-19 with other areas of concern from the multiplechoice questions emphasized food insecurity, serious illness and chronic illness care, as well as family violence, mental health and triggers of past trauma. In the domain of needing to move $(21 \%)$, the narratives strongly overlapped with multiplechoice domains of family violence, mental health and triggers of past trauma. Figure $2 \mathrm{C}$ shows that $40 \%$ of narratives emphasized the importance of being able to manage during the pandemic, followed by a balance of the ability to manage, the ability to make sense and to find meaning in the experience. Economic resources were the primary single resource needed (26\%); a cluster of resources was balanced between economic, cultural and social connections (27\%) (Figure 2D). Most support 


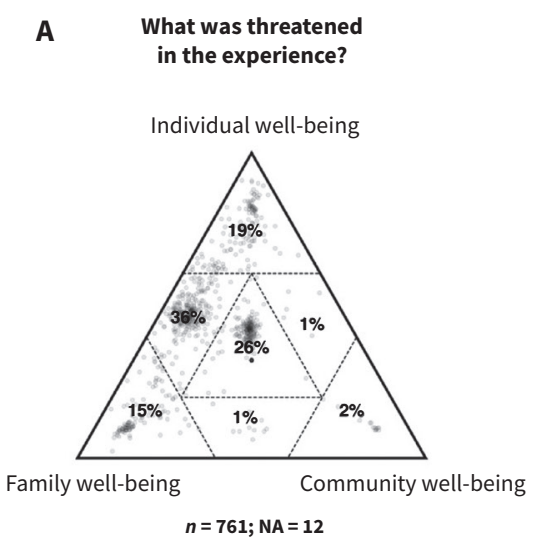

D

What resources were needed in this experience?

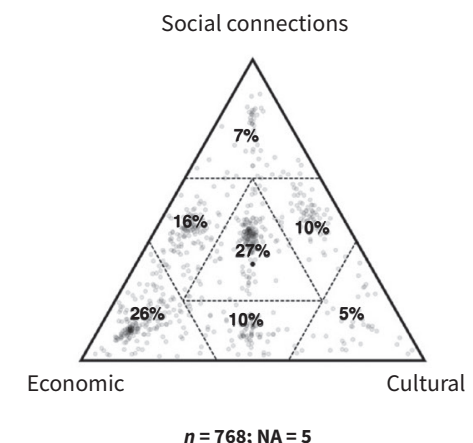

B In responding to the situation, the person/ people incurred risk by having to ...

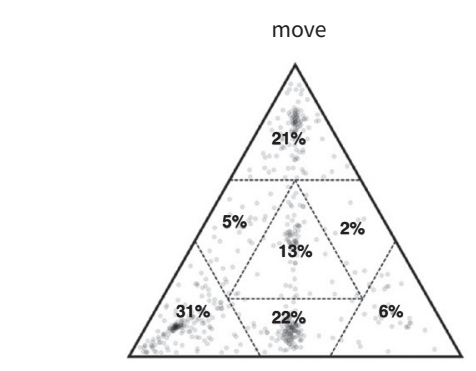

prioritize current needs reallocate resources

$n=589 ; \mathrm{NA}=184$

E
In this experience, sources of support came from ...

the MCHB, natural leaders

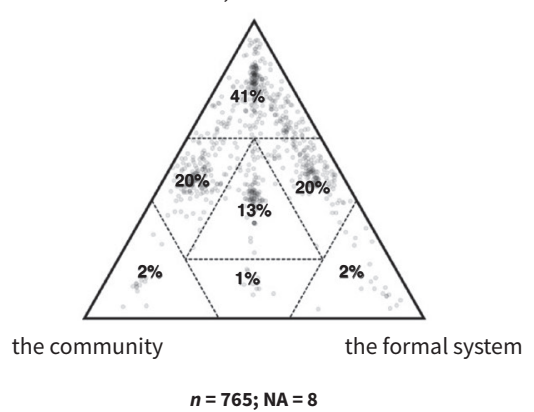

C

In this experience, what was important to the person/ people was ...

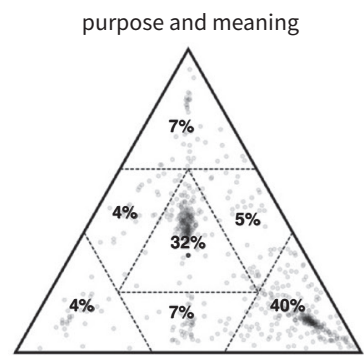

that things make sense to manage things $n=697 ; \mathrm{NA}=76$

$\mathbf{F}$

In this experience, where do you feel the most improvement could come from?

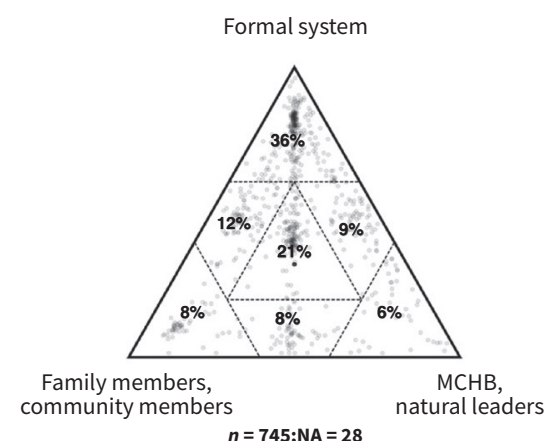

Figure 2: Visual summary of themes in signified micronarratives collected by peer researchers between Sept. 21, 2020, and Dec. 31, 2020, illustrating descriptive patterns in the triad's compositional data. Each dot in a triad represents a signified micronarrative. The same narrative is represented by a dot in the other triads. When recording their micronarratives, peer researchers respond to questions by indicating the degree to which their experience can be described by a corner of the triangle (e.g., for the question, "What resources were needed in this experience?" peer researchers position their response toward "Social connections," "Economic" resources or "Cultural" resources, depending on which best describes the experience. The closer the response to any one corner, the stronger that description fits in relation to the experience. Note: $n=$ the number of micronarratives in each triad, NA $=$ the number of narratives where that triad was not relevant in the peer researcher's interpretation.

$(41 \%)$ came from the MCHB or the MCHB, in concert with community or the formal system supports (Figure $2 \mathrm{E}$ ). Figure $2 \mathrm{~F}$ identifies the formal system as an area for improvement in $36 \%$ of narratives. A secondary cluster $(21 \%)$ was balanced between the need for improvement in the formal system, family and community members, and the MCHB and natural leaders.

The entangled thematic areas are presented in a social network analysis (Figure 3). This analysis highlights mental health concerns and the economic consequences of the pandemic, which intensify needs and require more brokering capacity to help people navigate the system

The concerns of individuals and families are multifaceted, as shown in the results of the multiple-choice questions in Figure 4. In the group analysis sessions, exploration of these domains in the linked narrative data illustrated various evolving and entangled issues relating to peoples' lived experience in the context of the pandemic, with the potential for multiple issues in one narrative. The 9 a priori areas of concern, identified by the peer researchers at the onset of the pandemic, were thus augmented with emerging domains, including legal concerns; the impact on children, youth and seniors; and a recognition that income insecurity is a core issue that is strongly associated with housing insecurity and food insecurity. Community social capital and cultural brokering that facilitated access to formal health and social system supports also emerged as thematic domains relating to how people were mitigating their areas of concern.

These domains were entangled in the narratives, as visualized in the social network analysis (Figure 3). This network view shows that entangled combinations of income, housing, food insecurity, COVID-19, mental health and family violence emerged more often in narratives than any other combination of domains identified.

\section{Sensemaking results}

The COVID-19 pandemic amplified disparities for people in vulnerable circumstances. Our participatory analysis showed the following 4 themes: increased intensity of peoples' basic needs; increased time and skill for brokers to support families' needs; increased effort and time to support communities' understanding of COVID-19 prevention and management; and identifying and leveraging community strengths to build social capital within and between communities, as well as with formal 


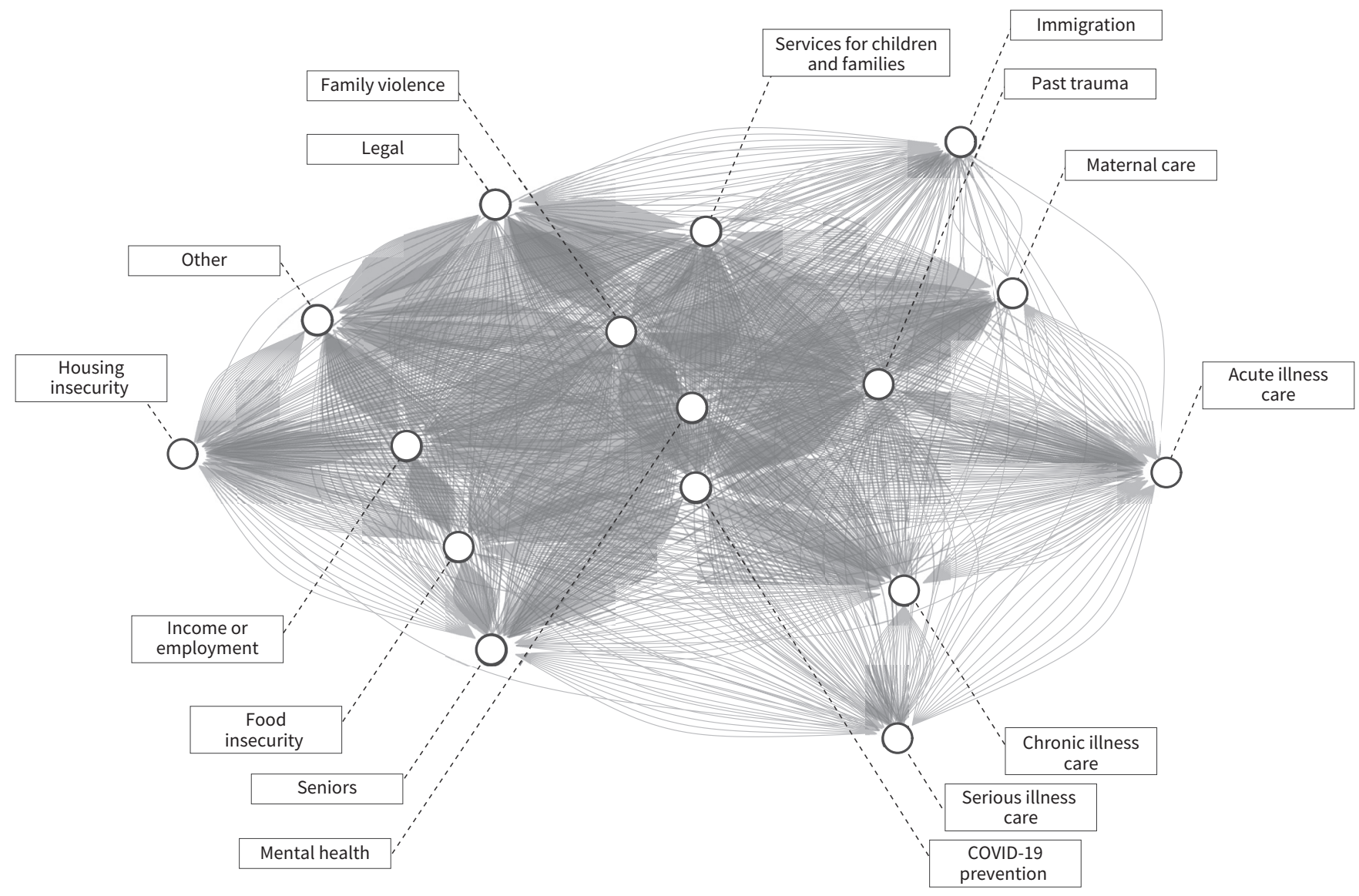

Figure 3: A network analysis of the identified thematic areas, represented as nodes (circles), with issue dyads represented by edges (solid line connections). Each edge represents 1 story that includes both themes represented by the connected nodes. Darker areas reflect higher concentrations of edges owing to more connections among particular themes. This nondirectional network includes 16 nodes and 2696 edges. The average degree of the network (the average number of ties across all nodes) is 336.4. For the subset of the network that includes only COVID-19 and instability in income, housing, and food ( 4 nodes) the average degree increases to 378.8 , which reflects the theme of increased intensity of needs during the COVID-19 pandemic. The average degree further increases to 427.4 when mental health is added to the subset ( 5 nodes), and to 473.3 when family violence is also added to the subset ( 6 nodes). The higher average degrees of the subsets of the network show that the average number of ties among these nodes is higher than for the network as a whole.

systems, as a key strategy to build resilience. Table 1 and Table 2 provide representative narratives that illustrate the themes. Supplemental data are in Appendix 4, available at www.cmaj.ca /lookup/doi/10.1503/cmaj.210131/tab-related-content; examples are highlighted in the text.

\section{Theme I. Increased intensity of needs}

We identified that financial insecurity, precarious employment and job loss are core issues hampering COVID-19 prevention and management, and exacerbating its impact on families' ability to meet basic needs. Requirements to isolate are more difficult to meet when income is tied to employment without paid sick time benefits, or with threats of job loss for missing work (Table 1, narrative 2). Quarantine is complicated by overcrowding in homes when extended or several families move in together given a lack of affordable housing or job loss (Table 1, narrative 1 and 3). The increased difficulty to meet basic needs and overcrowding is experienced as stress, and worsens problems with domestic violence and mental health.

Navigating health and social care services often requires interpretation and cultural brokering. Service delivery aimed at miti- gating these needs is hampered by access barriers to the use of online services (e.g., ongoing requirements for signed consent in person for broker assistance). Remotely accessing these services exacerbates existing language and cultural barriers (Table 1, narrative 4). The lack of technology in the homes of many newcomers (Appendix 4, narrative 3) not only affects peoples' access to online services, but also affects their children's education as schools shift to online learning, with substantial effects on youth education and well-being. The data highlight serious challenges over this time period for youth of South Sudanese and Somali descent, including substance abuse, violence and death, as well as illustrating brokers' efforts to connect with youth and identify meaningful supports (Table 1, narrative 5).

Theme II. Increased time and skills required to support families Brokers and natural leaders in the community use a relational and holistic approach to help people manage their complex situations (Appendix 5, available at www.cmaj.ca/lookup/doi/10.1503/ cmaj.210131/tab-related-content). The increased urgency and need of families for food, income support, housing and emergency 


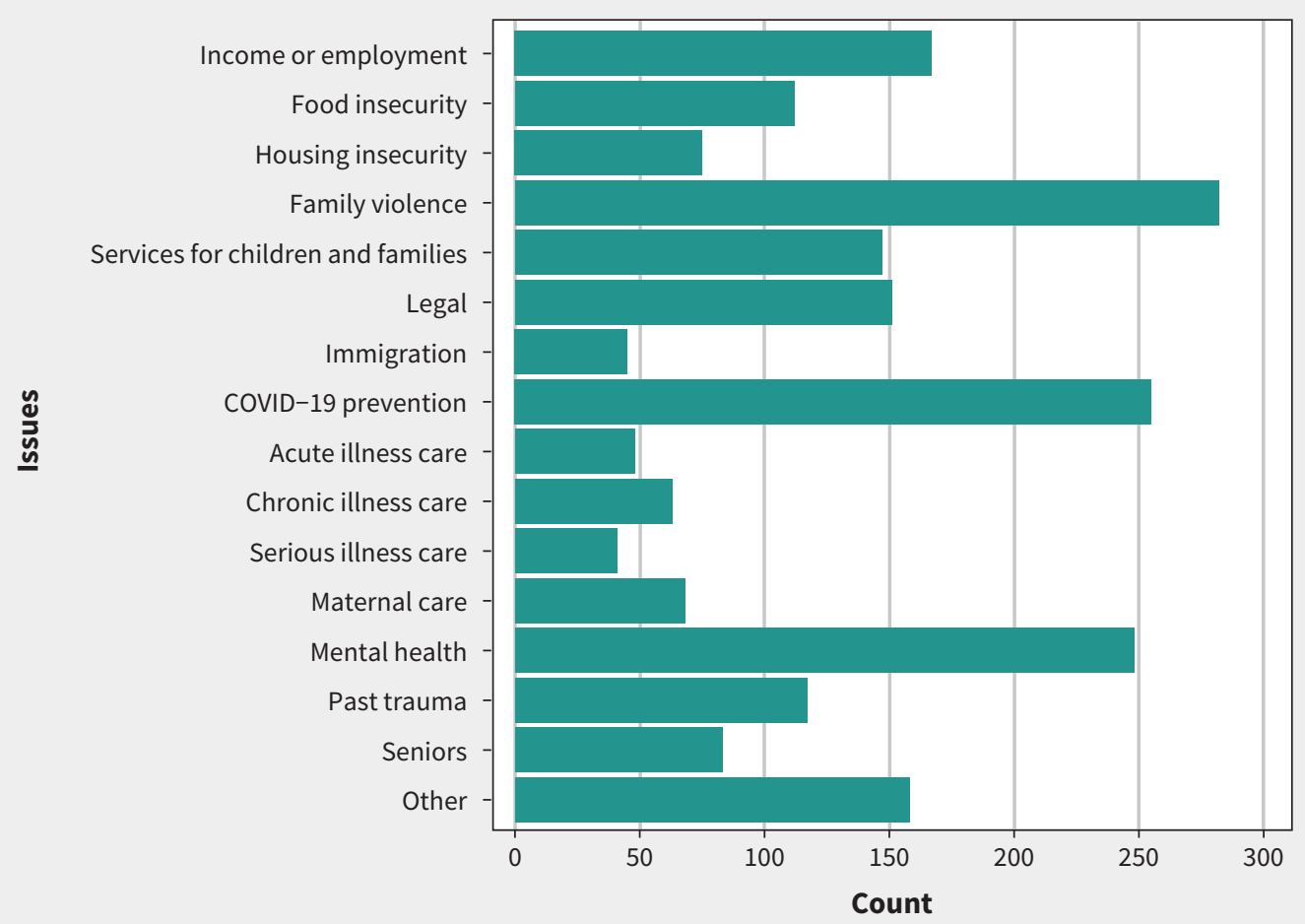

Figure 4: Issues affecting ethnocultural communities identified in the 773 narratives. Each narrative may include multiple themes.

quarantine support strains the resources of the brokers to manage their workloads (Table 1, narrative 3). The data show that initiatives such as the MCHB help make government support programs for COVID-19 work for people, fill the gaps in funding and support (Table 1, narrative 14; Appendix 4, narratives 3-6, 11), and advocate on the system and program levels to influence community and institutional responses to the systemic challenges of COVID-19.

Supporting virtual interactions with service agencies requires extensive efforts by brokers that are invisible to the formal system. The narratives show the intense support that brokers provide in navigating children's services and disability supports (Appendix 4, narrative 8), the criminal justice system (Appendix 4, narrative 7 ), and the health system (Table 1 , narrative 9). Pandemic support programs for income security, such as the Canada Emergency Response Benefit, are valued by communities, but changing regulations and processes make navigation challenging (Table 1, narrative 7). Seniors face substantial challenges with language and technology (Appendix 4, narratives 3, 5, 6).

Theme III. Increased time and resources to support community understanding of COVID-19 information and to manage impacts of the pandemic

Data highlight a high degree of misinformation within many communities because of language barriers and cultural distance in the way community members receive and understand information. Many narratives describe formal systems presenting barriers to accessing public services, and discussion in the group highlighted that this could exacerbate mistrust of formal systems among people who have had premigration trauma (Table 1, narratives 10-11). Fears of the repercussions of revealing positive tests or symptoms of SARS-CoV-2 infections to other community members affect contact tracing efforts. These repercussions include being blamed for passing on the disease to others, especially where there is death, stigma, and losing jobs that are temporary or "on call" if they have to isolate. Additionally, the widespread misinformation surrounding COVID-19 is amplified in ethnocultural communities, where inconsistent access to reputable information causes further mistrust and confusion (Table 1, narratives 11-14). The MCHB is working with health system partners to enhance community education and support (Appendix 4, narrative 11 and 12).

Theme IV. Identifying and leveraging community strengths and social capital within and between communities, as well as with formal systems, as a key strategy to build resilience

Narratives illustrate the strengths and the well-established communication networks within the communities (Table 2). They highlight the strong sense of community and solidarity, where members of the community are ready to give money, time and other resources to support each other in times of difficulty. The clusters of narratives in Figure 2E, positioned between MCHB and natural leaders, and both community and formal systems, point to the community development and intermediary roles of the $\mathrm{MCHB}$. The data illustrate that identifying and leveraging community strengths to build social capital within and between communities, as well as with formal systems, has been a key strategy to mitigate isolation and mobilize support. 


\section{Theme I. Increased intensity of needs}

1 "We have people in the community who live in very small housing with large families and therefore self- isolation is often very difficult inside the house and often becomes dangerous when there are elder parents. Therefore, brokers have to work with community members to find temporary safe placement for people who are required to self-isolate."

2 "Community members are not self-isolating or taking COVID-19 tests because they fear lost income or losing employment. Some also fear it may impact their applications for Permanent Residence if they self-isolate and are not able to support themselves. This is because some have self-isolated and lost income ... and were not able to meet their financial obligations."

3 "A large family, mother, father and 6 children (ranging in age from preschool to teenage) tested positive for COVID this weekend. The mother called the broker crying, saying they had no one to bring them groceries, and they were not allowed to go out due to self-isolation requirements. The mom said her children were very ill and shivering and asked if it was ok to give them Advil [...] Thus, broker went and bought milk, eggs, ginger, lemon, and some fruit - as well as Tylenol for adults and kids and dropped to family. This family has been on the waitlist for Capital Region Housing for 5 years - and currently resides in either a 2- or 3-bedroom apartment. The teenager got sick and got checked - tested positive for COVID, which is what led the rest of the family to get tested."

4 "Yesterday, talking with a broker, she shared that even though she was on the line with clients, the worker from Alberta Works insisted on getting different interpreters from the respective communities of the clients [...] The client was reapplying for Alberta Works, and although the broker could have easily provided a file number, and all the information would have come up - they insisted on going through spelling the client's name ... The broker was instructed not to speak - and in the middle of the call, the client was pleading with the broker to take over the interpretation. [...] The tragedy is that if the broker did not stay on the line - the client would risk being told they are ineligible because they cannot adequately explain their situation."

5 "This weekend, our South Sudanese colleagues working hard to support their community members to respond to the number of deaths in the community reflected [...]. They noticed that $75 \%$ of the deaths within the community since COVID-19 are those of youth and young adults (15 to 30 ). So they went further by visiting a group of youth similar to the ones who passed away recently. They learned a lot from 9 youth they visited. All of these youth were struggling with high alcohol use, not working and living in an over-crowded situation given poverty. Some have been in trouble with the law and have gone to jail. They need support with finding work, being involved in positive and health enhancing activities as well as support for the trauma they have experienced as second generation youth connected to their parents' trauma. [...] Broker colleagues will approach ECF [Edmonton Community Foundation] for potential funding for a youth engagement project."

\section{Theme II. Increased time and skills required to support families}

6 "The team of Senior Outreach Brokers met [...] to reflect and respond to the emerging struggles of our seniors and community members negatively impacted by COVID-19. With the emergency funding from the provincial government, the team, in partnership with SAGE [Seniors Association], was able to address social isolation with equipping 48 of the most vulnerable seniors within the 13 ethnocultural communities to have cellphones. One of our Brokers who has been able to support Syrian seniors to use cellphones for Zoom meetings will be teaching the Brokers to support the seniors to learn to use the cellphones."

7 "The federal government rushed to put the CERB [Canadian Emergency Response Benefit] in place, but realized it had many failings. Now everyone on CERB has to transition from this to El [Employment Insurance], Canada Recovery Benefit, CR Sickness B, or C Caregivers RB. The CRB, CRSB, CCRB are not available for application right now. This leaves many without the resources to pay their October 1 rent. It will also leave brokers scrambling to re-apply for many of their clients due to language barriers, lack of access to Internet [...]. This additional stress on our under-resourced organization is invisible to the Federal Government."

8 "Seniors often are coming to me to help them with financial literacy for example how to pay, read and manage their monthly bills.[...] We had weekly workshops before corona on these issues but we cannot do that now. During corona, they are calling me and taking pictures of their monthly bills and how to manage and pay them. If these bills go unpaid then it will have negative consequences [...] therefore, it is very important that I answer their needs and respond any way that I can."

9 "Prenatal moms who do not speak the language nor are familiar with health care systems are admitted to the hospital for their labour with very little support, as they do not have family members here and therefore rely solely on brokers. It is becoming very difficult during COVID because brokers cannot be with patients and therefore nurses and community members are calling brokers to support them over the phone with treatment, discharge papers but most importantly having a support system."

Theme III. Increased time and resources to support community understanding of COVID-19 information and to manage impacts of the pandemic

10 "A single mom [...] has had ongoing struggles getting the services she and her child with a disability need from FSCD [Family Support for Children with Disabilities]. She reports being demeaned go back to where you came from in her conversations with government workers. The difficulties mostly stem from cultural barriers as well as low literacy and numeracy - so forms are not always completed properly, and contracts may be misunderstood. With several emails, a conversation with a manager that helped identify mom's strengths, her history of trauma, and our role to bridge cultural and linguistic distance they began to become more flexible. Mom is considering signing a new agreement [...] she might be becoming more flexible as well."

11 "A broker shared a story of a family that is so scared of COVID-19 they will not go to appointment to get baby immunized. However, now they are even more scared to leave their home because baby is not immunized. This was shared in a meeting where co-op is trying to figure out a range of messaging to support community well-being at this difficult time."

12 "Community people with low literacy level experiencing hardship making an appointment for COVID 19 test by calling 811 - Misunderstanding of the protocol and advice from AHS [Alberta Health Services]."

13 "My client called me saying a staff working at the shelter she is staying at just confirmed is COVID-19 positive. AHS will send nurses to the shelter to test everyone. She is scared that she might have it because she has sore throat. Told her not to go out and wait for the test. But later she told me she went out to have lunch because she saw other families also went out, no one from the shelter stopped them. Encouraged her not to go out anymore and to follow the AHS guideline."

14 "At the team meeting of the Brokers who provide outreach support to seniors in 11 communities, there was a lot of concern about the growing number of individuals tested positive as well as more deaths within the communities. There is a deep desire within the team to bring more effectively message about COVID-19, how to keep safe and how to respond once a person is tested positive. [...] We talked about [...] needing to engage the most influential messengers (including faith leaders). The idea of having AHS colleagues provide information directly to our community members with us translating through Zoom emerged and we will be pursuing this with Dr. X (Medical Office of Health)."

*Supplemental data are in Appendix 4. Narratives are lightly edited to condense length. 
- "I got a call from a member of my own community [...] She used to work as a live-in nanny full time. However, because of the COVID pandemic, her female employer was laid off and decided to take care of her children herself and asked the nanny to leave her job. The nanny shared that her children just arrived from the Philippines to be finally reunited with her after years of waiting. She felt so helpless [...]. This broker connected her with the other members of the community and shared her plea through the community's ethnocultural channels, Facebook groups, etc. [...] she called back to share that through those channels she was hired as a full-time employee of a cleaning company."

- "Currently there is a high number of COVID cases within the community therefore members are seeking help with organizing/scheduling tests. Many of the non-literate community members do not have capacity to book a COVID test online or by the phone therefore they are calling other community members and brokers to book testing."

- "Writer received a call from a mother that she is getting surgery in a week that will need hospitalization for at least 3 days. She is concerned about the care of her children as she doesn't have anyone to look after the children [...] Fortunately, writer was able to connect with the mother with another mother who looked after the children without a pay."

- "Newcomer Youth who was in isolation due to corona virus lives with elderly parents [...], he did not know how to isolate from his parents in a cramped apartment that already has many people living in it. Broker worked with community members to get the youth placed in a bigger home of a community member until he was in the clear from corona virus."

- "Proud of Chinese team, within 2 weeks of lockdown, put together virtual options, including a weekend program. Three programs in a week. Every week a specific topic, recently bicultural parenting, Children Services programs, etc. Through drawing and painting increasing connection for parents and children. Expanding during COVID rather than contracting."

*Narratives are lightly edited to condense length.

\section{Discussion}

In this study, we have illustrated the entangled impacts of COVID-19 on individuals and families living in vulnerable circumstances in ethnocultural communities in Edmonton. This increased understanding can inform action by the MCHB, the community and formal systems. Findings highlight the syndemic effect when COVID-19 intersects with pre-existing conditions in the context of socioeconomic inequities and structural barriers to accessing supports for these communities. Despite the communities' use of resilience processes, such as mobilization of cultural, social, and economic resources, to support one another, families face disproportionate challenges in mitigating the social and economic impacts of COVID-19 and in accessing relevant information and formal support. A key finding is the impact COVID-19 has had in destabilizing the family unit, thereby increasing the time and resources needed to support families. Given the misalignment of formal system processes with the realities of people in vulnerable socioeconomic conditions, these challenges resulted in substantial access barriers to services and the vital need for cultural brokering. We were able to distill several practical suggestions to inform policy and action from our findings (Appendix 6, available at www.cmaj.ca/lookup/ doi/10.1503/cmaj.210131/tab-related-content). We identified the need for supports for distancing and isolation requirements, adjustment of processes and documentation requirements for formal health and social care systems, employment security and support for labour market attachment, and actions to mitigate the pandemic's impact on children and youth.

We also illustrated the importance of cultural brokers in bridging between people, communities and formal systems to build and sustain trusting relationships. Brokers possess deep knowledge of community strengths and risks, such as socioeconomic conditions that can create risk ${ }^{42}$ for increased infection and death. Others have also shown that cultural brokering can help to mitigate the impacts of COVID-19, providing people with the necessary resources to avert escalation of harm and a sense of agency in challenging situations..$^{23}$ We observed a tremendous increase in the time needed for the brokers to navigate access to resources, to support public health measures and to relay information and education to community members in meaningful ways. Timely reflection and learning to inform action, along with building the right relationships in the different spheres for action, were necessary to support change in this complex situation. The MCHB used the knowledge created in this project to adjust its system- and community-level advocacy efforts, in addition to individual brokering with families in crisis.

The surge of COVID-19 in ethnocultural communities across North America, and the pandemic's destabilizing effect on health care systems, has highlighted existing core issues with systemic structures that result in poorer health in ethnocultural communities. Consequently, creating a deeper shared understanding between people and systems must be made a priority for health and social care systems. ${ }^{4,6,8,10,44}$ Cultural brokering is crucial to this process, as it involves the following key elements: liaising or coming together to build holistic caring relationships; mobilizing knowledge of systems and people bidirectionally; mediation and building trust by clarifying misunderstandings of both systems and people to reduce cultural distance, which is predicated on safe relationships; and making change through action, through which both the individual and the system can be transformed..$^{20,22}$

In their conceptual framework of integration, Ager and Strang ${ }^{45}$ point to social capital as the connective tissue between public outcomes (i.e., in health, education, employment and housing) and foundational citizenship rights, seen as the basis for "full and equal engagement within society." They identify 3 types of social capital, namely social bonds (with family and coethnic groups), social bridges (with other communities) and social links (with structures of the state). The role of relational brokering, supported by smart public policy, is to help 
strengthen communities and families' sense of security and ability to mobilize resiliency resources.

A lack of systematically collected data on race and ethnicity has challenged our understanding of the impact of COVID-19 on ethnocultural communities. The particular vulnerabilities of visible minority communities to the effects of the COVID-19 pandemic demand the collection of disaggregated data. ${ }^{9,44}$ Currently, coalitions of representatives from multicultural organizations, municipal and provincial governments, and the health system are working together to craft interventions aimed at mitigating the health and social impacts of COVID-19. A crucial aspect of this work will be to leverage existing community resources, such as trusted communication channels, cultural and social resources, to contextualize interventions for different communities. This will lead to more meaningful and sustainable interventions, since health interventions that are adapted for local contexts and community characteristics tend to be more effective than standard approaches..$^{46,47}$

\section{Limitations}

We collected data on vulnerable members of ethnocultural populations in only 1 large urban centre in Canada. Although many findings may be relevant to other contexts, some may not because of contextual nuances. We used relatively new methods, implemented and adapted rapidly in a crisis situation to existing research infrastructures. Our use of SenseMaker data may illuminate only part of a complex story, highlighting opportunities for further study by other methods. More detailed qualitative work with conventional methods would be helpful to explore the themes uncovered in this study. However, our findings may help inform the design of interventions aimed at minimizing the harms of COVID-19 for ethnocultural communities. In this participatory action research study, data collection and analysis were done with members of the MCHB workers' co-operative. Although many of the impacts may apply broadly to different groups of people in vulnerable circumstances, more impacts and nuances may be illuminated by expanding micronarrative collection to others working in service organizations focused on different community segments

\section{Conclusion}

The Illuminate Project has shown the entangled, systemic issues that result in poor health among people in vulnerable circumstances in ethnocultural communities, and the exacerbating impact of COVID-19, which also increased barriers to mitigation. Cultural brokering and community social capital were key supports for people in this crisis, and our findings can support policy and interventions that may reduce harm and support community resiliency.

\section{References}

1. Applicants assisting ethnocultural communities. Ottawa: Government of Canada; 2019 Dec. 18. Available: https://www.canada.ca/en/revenue-agency/services/ charities-giving/charities/policies-guidance/policy-statement-023-applicants -assisting-ethnocultural-communities.html (accessed 2021 July 1).

2. Castañeda H, Holmes SM, Madrigal DS, et al. Immigration as a social determinant of health. Annu Rev Public Health 2015;36:375-92.

3. Clark B, Preto N. Exploring the concept of vulnerability in health care. CMAJ 2018;190:E308-9.
4. Baum KB, Carrie T, Tavia G. How Cargill became the site of Canada's largest single outbreak of COVID-19. The Globe and Mail [Toronto] 2020 May 2. Available: https://www.theglobeandmail.com/business/article-how-cargill-became-the -site-of-canadas-largest-single-outbreak-of/ (accessed 2020 Dec. 14).

5. LaRochelle-Côté S, Uppal S. The social and economic concerns of immigrants during the COVID-19 pandemic. 2020 Available: https://www150.statcan.gc.ca/ n1/pub/45-28-0001/2020001/article/00012-eng.htm (accessed 2021 May 10].

6. Yancy CW. COVID-19 and African Americans. JAMA 2020;323:1891-2.

7. Thebault R, Tran AB, Williams V. The coronavirus is infecting and killing black Americans at an alarmingly high rate. Washington Post 2020 Apr. 7. Available: https://www. washingtonpost.com/nation/2020/04/07/coronavirus-is-infecting-killing-black -americans-an-alarmingly-high-rate-post-analysis-shows/ (accessed 2021 May 10).

8. Webb Hooper M, Nápoles AM, Pérez-Stable EJ. COVID-19 and racial/ethnic disparities. JAMA 2020;323:2466-7.

9. Wadhera RK, Wadhera P, Gaba P, et al. Variation in COVID-19 hospitalizations and deaths across New York City boroughs. JAMA 2020;323:2192-5.

10. Millett GA, Jones AT, Benkeser D, et al. Assessing differential impacts of COVID-19 on Black communities. Ann Epidemiol 2020;47:37-44.

11. Update on COVID-19 testing in Alberta [L3 COVID-19 webinar series]. Edmonton: University of Alberta; 2020. Available: https://www.youtube.com/watch?v=LTC wM8vQdC0\&feature=youtu.be (accessed 2021 Jan. 10).

12. Sligl W, Waldner D; Royal Society of Canada. The epidemiology of COVID-19 in Canada in 2020: the pre-vaccine era [RSC Policy Briefing]. Ottawa: Royal Society of Canada; 2021. Available: https://login.ezproxy.library.ualberta.ca/login? url=https://search.ebscohost.com/login.aspx?direct=true\&db=edscel\&AN=edscel $.10106588 \&$ site=eds-live\&scope=site (accessed 2021 May 3).

13. van der Merwe SE, Biggs R, Preiser R. Sensemaking as an approach for resilience assessment in an essential service organization. Environ Syst Decis 2020;40:84-106.

14. Snowden D, Rancati A. Managing complexity (and chaos) in times of crisis. A field guide for decision makers inspired by the Cynefin framework. Luxembourg: Publications Office of the European Union; 2021. Available: https://publications.jrc. ec.europa.eu/repository/handle/JRC123629 (accessed 2021 Mar. 28).

15. Minkler M. Using participatory action research to build healthy communities. Public Health Rep 2000;115:191-7.

16. Reason $\mathrm{P}$, Bradbury $\mathrm{H}$, editors. The SAGE handbook of action research: participative inquiry and practice. Thousand Oaks (CA): Sage Publications; 2001.

17. Wallerstein NB, Duran B. Using community-based participatory research to address health disparities. Health Promot Pract 2006;7:312-23.

18. Israel B, Schulz A, Parker E, et al. Critical issues in developing and following community based participatory research principles. In: Minkler M, Wallerstein $\mathrm{N}$, editors. Community based participatory research for health. San Francisco: Jossey-Bass; 2003:53-76.

19. O'Cathain A, Murphy E, Nicholl J. The quality of mixed methods studies in health services research. J Health Serv Res Policy 2008;13:92-8.

20. Jezewski MA. Culture brokering in migrant farmworker health care. West J Nurs Res 1990;12:497-513.

21. Voith LA, Hamler T, Francis MW, et al. Using a trauma-informed, socially just research framework with marginalized populations: practices and barriers to implementation. Soc Work Res 2020;44:169-81.

22. Multicultural Health Brokers | Multilingual, Culturally Diverse Services for Immigrants and Refugees. Edmonton: The Multicultural Health Brokers Co-operative. Available: http://mchb.org/ (accessed 2020 Dec. 27).

23. Bridging the cultural divide in health care settings: the essential role of Cultural Brokers Program. Washington (D.C.): National Center for Cultural Competence. Georgetown University; 2004. Available: https://nccc.georgetown.edu/ culturalbroker/11_contents/index.html (accessed 2020 Dec. 27).

24. Triandis HC. 10.01 - Introduction to diversity in clinical psychology. In: Bellack AS, Hersen M, editors. Comprehensive clinical psychology. Oxford (UK): Pergamon; 1998:1-33. Available: https://www.sciencedirect.com/science/article/ pii/B0080427073001036 (accessed 2021 May 23).

25. Bruner JS. Actual minds, possible worlds. Cambridge (MA): Harvard University Press; 1986:201.

26. Natasi BK, Hitchcock JH, Brown LM. An inclusive framework for conceptualizing mixed methods design typologies: moving toward fully integrated synergistic research models. In: SAGE handbook of mixed methods in social \& behavioral research. 2nd ed. Thousand Oaks (CA): SAGE Publications; 2010:305-38. Available: https://methods.sagepub.com/book/sage-handbook-of-mixed-methods-social -behavioral-research-2e (accessed 2021 May 20). 
27. Christ TW. Teaching mixed methods and action research: pedagogical, practical, and evaluative considerations. In: SAGE handbook of mixed methods in social \& behavioral research. 2nd ed. Thousand Oaks (CA): SAGE Publications; 2010: 643-76. Available: https://methods.sagepub.com/book/sage-handbook -of-mixed-methods-social-behavioral-research-2e (accessed 2021 Apr. 20).

28. Snowden D, Goh Z, Borchardt S. Cynefin: weaving sense-making into the fabric of our world. In: Greenberg R, Bertsch B, Blignaut S, editors. Singapore, United States, United Kingdom: Cognitive Edge; 2021.

29. Van der Merwe SE, Biggs R, Preiser R, et al. Making sense of complexity: using SenseMaker as a research tool. Systems 2019;7(2).

30. Milne KMG. Can sense-making tools inform adaptation policy? A practitioner's perspective. Ecol Soc 2015;20:66 Available: https://www.ecologyandsociety. org/vol20/iss1/art66/ (accessed 2021 Apr. 20).

31. Mattingly CF. Acted narratives: from storytelling to emergent dramas. In: Handbook of narrative inquiry: mapping a methodology. Thousand Oaks (CA): Sage Publications; 2007:405-25. Available: https://methods.sagepub.com/book/handbook-of -narrative-inquiry/n16.xml (accessed 2020 Dec. 30).

32. Singer MC, Erickson PI, Badiane L, et al. Syndemics, sex and the city: understanding sexually transmitted diseases in social and cultural context. Soc Sci Med 2006;63:2010-21.

33. Tsai AC, Mendenhall E, Trostle JA, et al. Co-occurring epidemics, syndemics, and population health. Lancet 2017;389:978-82.

34. Easton D. The urban poor. In: Ember C, Ember M, editors. Encyclopedia of medical anthropology. New York: Kluwer; 2004: 207-13.

35. Antonovsky A. Health, stress, and coping. San Francisco: Jossey-Bass; 1979.

36. The handbook of salutogenesis. In: Mittelmark MB, Sagy S, Eriksson M, et al., editors. Cham (Switzerland): Springer; 2017.

Competing interests: Denise Campbell-Scherer reports participating on the Pfizer advisory panel on obesity, outside the submitted work. Yvonne Chiu is the executive director of the Multicultural Health Brokers Cooperative (MHBC) and acknowledges that MHBC relies on government grants for its operations and program delivery. Ali Mahdi, Aline Gayawira, Fransiska Awasis, Funke Olokude, Hannah Goa, Hina Syed, Judy Sillito, Lydia Yip, Lyn Belle, Mawien Akot, Monique Nutter, Nadia Farhat, Yan Wang, Niga Jalal, Saida Khalif, Shiva Chapagain, Stephanie Fernandez, Susan Azarcon, Zhewar Hama are employees of the MHBC. No other competing interests were declared.

This article has been peer reviewed.

Affiliations: Office of Lifelong Learning \& the Physician Learning Program, Faculty of Medicine and Dentistry (Campbell-Scherer, Hunter, Luig), University of Alberta; Department of Family Medicine, Faculty of Medicine and Dentistry (Campbell-Scherer, Ofosu, Jabbour), University of Alberta; Multicultural Health Brokers Cooperative (Chiu, Mahdi, Gayawira, Awasis, Olokude, Goa, Syed, Sillito, Yip, Belle, Akot, Nutter, Farhat, Wang, Jalal, Khalif, Chapagain, Fernandez, Azarcon, Hama); University of Alberta Medical School, Faculty of Medicine and Dentistry (Farooq); Alberta Diabetes Institute (Campbell-Scherer), University of Alberta, Edmonton, Alta.

Contributors: Denise Campbell-Scherer and Yvonne Chiu conceived the project idea. Denise Campbell-Scherer, Nicole Naadu Ofosu, Karen Heather Hunter, Yvonne Chiu designed the study methods. Denise Campbell-Scherer, Yvonne Chiu, Nicole Naadu Ofosu, Badi Jabbour, Sauleha Farooq, Ali Mahdi, Aline Gayawira, Fransiska Awasis, Funke Olokude, Hannah Goa, Hina Syed, Judy Sillito, Lydia Yip, Lyn Belle, Mawien Akot, Monique Nutter, Nadia Farhat, Yan Wang, Niga Jalal, Saida Khalif, Shiva Chapagain, Stephanie Fernandez, Susan Azarcon and Zhewar Hama created the data collection tools, supported data collection and contributed to the participatory data analysis. Denise CampbellScherer, Yvonne Chiu, Nicole Naadu Ofosu, Karen Heather Hunter, Badi Jabbour and Sauleha Farooq and supported the mixed-methods data analysis, with Karen Heather Hunter supporting the quantitative data analysis. Denise Campbell-Scherer, Yvonne Chiu, Nicole Naadu Ofosu,
37. Estêvão P, Calado A, Capucha L. Resilience: moving from a "heroic" notion to a sociological concept. Sociol Probl E Práticas 2017;85:9-25. Available: https:// revistas.rcaap.pt/sociologiapp/article/view/10115/9696( accessed 2021 Jan. 15).

38. Frank A. Practicing dialogical narrative analysis. In: Varieties of narrative analysis. 2012:33-52.

39. Holloway I, Freshwater D. Narrative research in nursing. Chichester (UK): WileyBlackwell; 2007.

40. Bester E. About SenseMaker ${ }^{\circledast}$. Singapore, United States, United Kingdom: Cognitive Edge. Available: https://sensemaker.cognitive-edge.com/what-is-sensemaker/ (accessed 2020 Dec. 22).

41. Snowden DJ. Multi-ontology sense making: a new simplicity in decision making. Inform Prim Care 2005;13:45-54.

42. Scott J. Social network analysis: a handbook. London (UK): Sage publications; 1987.

43. Borgatti S, Everett M, Johnson J. Analyzing social networks. Thousand Oaks (CA): Sage Publications; 2013.

44. Subedi R, Greenberg L, Turcotte M. COVID-19 mortality rates in Canada's ethno cultural neighbourhoods. Ottawa: Statistics Canada; 2020. Available: https:// www150.statcan.gc.ca/n1/pub/45-28-0001/2020001/article/00079-eng.htm (accessed 2020 Dec. 23).

45. Ager A, Strang A. Understanding integration: a conceptual framework. J Refug Stud 2008;21:166-91.

46. WHO framework on integrated people-centred health services. Geneva: World Health Organization; 2016. Available: http://www.who.int/servicedeliverysafety /areas/people-centred-care/en/ (accessed 2021 Jan. 15).

47. Smith TB, Rodríguez MD, Bernal G. Culture. J Clin Psychol 2011;67:166-75

Thea Luig, Badi Jabbour, Sauleha Farooq, Karen Heather Hunter and Monique Nutter wrote the manuscript. All authors revised it critically for important intellectual content, gave final approval of the version to be published and agreed to be accountable for all aspects of the work. Denise Campbell-Scherer and Yvonne Chiu share joint first authorship.

Content licence: This is an Open Access article distributed in accordance with the terms of the Creative Commons Attribution (CC BY-NC-ND 4.0) licence, which permits use, distribution and reproduction in any medium, provided that the original publication is properly cited, the use is noncommercial (i.e., research or educational use), and no modifications or adaptations are made. See: https://creativecommons.org/ licenses/by-nc-nd/4.0/

Funding: This study was supported by the Illuminate Lab Associate Dean discretionary research funds, with in-kind support from the NOVAD Grant (University Hospital Foundation, Novo Nordisk, Alberta Economic Development and Trade) and from the Physician Learning Program (PLP). The PLP is funded by Alberta Health, supported by a financial contribution from the Government of Alberta. The views expressed herein do not necessarily represent the official policy of the Government of Alberta.

Data sharing: These data are the product of a participatory research collaboration in a sensitive context that requires the engagement of peer researchers with lived experiences in interpretation of the data, as described. The authors do not feel it would be appropriate to share data beyond what has been vetted by the collaborative and is shared in the appendix.

Acknowledgements: The authors thank Anna Panagiotou and Prof. David Snowden for their helpful discussions on anthrocomplexity and SenseMaker for this project. The authors also acknowledge the work of Jordan Tate from the Physician Learning Program for the visualization of the research process.

Accepted: July 6, 2021

Correspondence to: Denise Campbell-Scherer, dlcampbe@ualberta.ca 